\title{
Bias versus bias: Harnessing hindsight to reveal paranormal belief change beyond demand characteristics
}

\author{
Michael J. Kane and Tammy J. Core \\ University of North Carolina, Greensboro, North Carolina \\ AND \\ R. REED Hunt \\ University of Texas, San Antonio, Texas
}

\begin{abstract}
Psychological change is difficult to assess, in part because self-reported beliefs and attitudes may be biased or distorted. The present study probed belief change, in an educational context, by using the hindsight bias to counter another bias that generally plagues assessment of subjective change. Although research has indicated that skepticism courses reduce paranormal beliefs, those findings may reflect demand characteristics (biases toward desired, skeptical responses). Our hindsight-bias procedure circumvented demand by asking students, following semester-long skepticism (and control) courses, to recall their precourse levels of paranormal belief. People typically remember themselves as previously thinking, believing, and acting as they do now, so current skepticism should provoke false recollections of previous skepticism. Given true belief change, therefore, skepticism students should have remembered themselves as having been more skeptical than they were. They did, at least about paranormal topics that were covered most extensively in the course. Our findings thus show hindsight to be useful in evaluating cognitive change beyond demand characteristics.
\end{abstract}

Psychology and its allied disciplines have long struggled to accurately assess change, whether that ostensible change results from maturation, senescence, laboratory experimental manipulations, psychotherapeutic techniques, community interventions, or educational programs (see, e.g., Cronbach \& Furby, 1970; Hertzog \& Nesselroade, 2003; Lord, 1956, 1967; Nesselroade, Stigler, \& Baltes, 1980; Rubin, 1974). Of course, in contexts in which the desired change is entirely subjective - as is the case with attitudes, beliefs, cognitions, evaluations, or emotional states - the risks of misidentifying or misinterpreting change will only increase, since subjects' self-reports may be biased, distorted, or erroneous (see, e.g., Conway \& Ross, 1984; Festinger, 1957; Greenwald, Spangenberg, Pratkanis, \& Eskenazi, 1991; Hoogstraten, 1979; Kirsch, 1985; Lewinsohn \& Rosenbaum, 1987; Loftus, 1979; H. Markus \& Kunda, 1986; Orne, 1962; Wilson \& Brekke, 1994). Researchers must therefore develop statistical and methodological tools to help discriminate real from illusory change. The present study demonstrated a seemingly paradoxical approach, whereby a powerful cognitive bias was strategically deployed as a means to counter another, especially formidable bias that plagues assessment of subjective change-here, in the context of an educational intervention designed to affect undergraduates' beliefs.

\section{Education and Paranormal Belief}

Most Americans, even many with advanced educational degrees, hold paranormal, superstitious, or pseudoscientific beliefs, such as belief in extrasensory perception (ESP), alien abduction, or creationism (Moore, 2005; Newport \& Strausberg, 2001; Rice, 2003). Indeed, neither general science knowledge nor a scientific major consistently hinders such beliefs (Aarnio \& Lindeman, 2005; Goode, 2002). Limited research suggests, however, that university courses that directly and skeptically examine paranormal and pseudoscientific phenomena may reduce students' beliefs in them, at least in the short term.

Unfortunately, this literature is limited in both size and methodological rigor. Of the dozen or so published studies on educational interventions and paranormal belief, only three included control groups (students in unrelated courses; see Dougherty, 2004; Gray, 1985; Morier \& Keeports, 1994); ${ }^{1}$ furthermore, some studies included only postcourse evaluations with no pre-to-post comparisons (Broch, 2000; Calvin, 2009), and most studies asked students to report their beliefs without anonymity (Banziger, 1983; Emme, 1940; Gilliland, 1930; Jones \& Zusne, 1981; McBurney, 1976; Swords, 1990; Tobacyk, 1983). Most reports of education-induced paranormal belief change may thus have derived simply from passing time (or other

M. J. Kane, mjkane@uncg.edu 
external influences) or from students' reaction to their identifiabilty. These are significant and rather obvious interpretive obstacles. However, even studies comparing paranormal-skepticism courses with controls, with anonymous belief reporting, likely suffered from an additional problem, demand characteristics (Orne, 1962): Students may simply have provided the instructor-as-investigator with the obviously desired responses (i.e., that they are now more skeptical of the paranormal than they were before). Of course, such demand characteristics may contaminate the assessment of any experimental, educational, or clinical interventions designed to change subjective outcomes (see, e.g., Laney et al., 2008). But is there a compelling way around them?

\section{Debiasing via Hindsight Bias}

The present study harnessed a much-studied cognitive bias - hindsight - as a novel means to circumvent demand characteristics in self-reported psychological change. Laboratory investigations of hindsight bias typically ask subjects to predict event outcomes or to answer trivia questions before providing them with the actual outcomes or answers (Fischhoff, 1975; for a review, see Hawkins \& Hastie, 1990). Hindsight bias occurs when outcome knowledge colors subjects' subsequent reports (and, ostensibly, beliefs) about their initial state of knowledge, such that they "knew it all along" (Hasher, Attig, \& Alba, 1981). Most relevant to the present study, hindsight has also been demonstrated beyond the cognitive psychology laboratory, with people's current attitudes and beliefs biasing their recollections of their own personal past, in a form of false memory (Ross, 1989). For example, when adults recall their adolescent political attitudes and beliefs, previous emotions, or substance use, their recollections are strongly influenced (and sometimes, most strongly influenced) by their current attitudes, beliefs, emotions, and behaviors, rather than by their actual past attitudes and behaviors (see, e.g., Collins, Graham, Hansen, \& Johnson, 1985; Field, Thompson, \& Gallagher-Thompson, 2006; G. B. Markus, 1986). This holds even following a challenge to one's beliefs, such as writing a counter-attitudinal essay: Students who chose to write an essay arguing against their belief that students should have considerable control over the courses taught at their university subsequently misremembered that they had previously held that belief much less strongly than they actually did (Bem \& McConnell, 1970). It seems, then, that adults generally hold implicit theories of belief and trait stability, even in the face of potentially change-inducing events, and so when they recall their past actions and opinions they are unduly influenced by their psychological present (Ross, 1989). Thus, if I am skeptical of the paranormal now, for example, then I am likely to remember myself - rightly or wrongly — as having been similarly skeptical in the past.

To exploit such hindsight systematically, we anonymously probed university students' paranormal beliefs preceding and following a semester-long skepticism course, versus control courses, in two ways. Half of each class reported their current beliefs at both times (the typical, demand-vulnerable procedure); the other half reported their current beliefs at Time 1 but tried to reproduce exactly their Time 1 responses at Time 2 from memory (the hindsight procedure). Given actual belief change (toward nonbelief), skepticism students should have reported their Time 2 paranormal beliefs to have been weaker than those at Time 1, and weaker than those of Time 2 controls. Moreover-and critically - with the hindsight procedure, they (but not controls) should have recalled themselves as having been more skeptical at Time 1 than they actually were.

\section{METHOD}

We compared pre- with postcourse paranormal beliefs in both skepticism courses (precourse $N=340$ ) and control courses (precourse $N=238$ ). The semester-long skepticism course (PSY 318, Belief in "Weird" Things) was taught over three different semesters by the first author at the University of North Carolina at Greensboro (UNCG), a comprehensive state university in the southeastern U.S. with an introductory psychology prerequisite (syllabi available at www.uncg.edu/ mjkane/memlab.html). Through lectures, readings, videos, and demonstrations (from classic memory experiments to mentalist magic tricks), the course focused on the philosophy and methods of science, the idea and perils of naive realism, various cognitive biases and illusions that may create and sustain false beliefs, and the empirical evidence (pro and con) regarding many paranormal and pseudoscientific phenomena. The instructor repeatedly made it clear that students would not be graded on the basis of their beliefs and that, beyond two anonymous surveys, they would never be asked to reveal their beliefs in the course context.

Control classes were three semester-long UNCG psychology courses with identical prerequisites, each taught by a different instructor (including one by the third author); they were survey courses in developmental psychology; cognitive psychology; and sex, gender, and behavior. Skepticism and control classes had equivalent subject-retention rates (56\% and 57\%, respectively) between Time 1 (precourse) and Time 2 (postcourse). Lost data reflected course withdrawals, isolated absences from class when questionnaires were administered, or students' failure to use the same identity-protecting PIN code on both pre- and postcourse questionnaires.

We collected belief-report measures from skepticism courses at the very beginning of the first and last classes, and from control courses some time during the first and last 1.5 weeks of the semester. At Time 1, all students responded according to their current beliefs. At Time 2, we color-coded belief measures and distributed them pseudorandomly from a shuffled pile (by seating); students who received questionnaires in one color reported their current beliefs (the typical procedure), and students who received them in the other color did so by recollecting their Time 1 belief reports (the hindsight procedure). To emphasize to hindsight-questionnaire students that we wanted them to accurately recall their prior beliefs in an unbiased way (i.e., to create an "experimental demand" for memory accuracy; Bem \& McConnell, 1970; Fischhoff, 1977), we wrote the following instructions on the questionnaires and reinforced them orally: "Please read each statement and try to recall how strongly you either believed or disbelieved in it the last time you completed this questionnaire, by circling a number from 1-7. We do not want you to respond according to your current beliefs, but rather according to your beliefs before you took this course..." (all emphases in the original). Students created PIN codes for their Time 1 and Time 2 measures to allow anonymous linking of individual students' preand postcourse responses. We collected no demographic information, in order to satisfy IRB concerns about student anonymity given that the subjects were also the investigators' students.

The belief-report measure presented 52 items representing seven categories: psychics/ESP, alternative medicine/healing, superstitions/omens, UFOs/alien abduction, astrology, creationism, and Judeo-Christian/biblical (for the complete measure, see www 
.uncg.edu/ mjkane/memlab.html). Judeo-Christian/biblical beliefs, aside from creationism, were not addressed in the course materials but acted as a control category. For all items, students rated their belief on 7-point scales anchored by 1 (strongly disbelieve), 4 (unsure), and 7 (strongly believe). Principal components analysis (oblimin rotation) on all Time 1 data $(N=578)$ yielded seven components with eigenvalues greater than 1 . To simplify the data and to best represent the skepticism-course topics, we selected the five or six highest loading items from each component, after splitting one component into separate Judeo-Christian/biblical and creationism categories (because only the latter reflected course material) and combining a single-item meditation component with the related alternative medicine/healing component (see Table 1); we then averaged the five to six item scores for each belief category and for each student (after reverse scoring any items with negative component loadings), and analyzed those mean category scores. ${ }^{2}$

\section{RESULTS AND DISCUSSION}

We analyzed belief-change data only from the students who completed both Time 1 and Time 2 measures $(N=$ 190 and $N=136$ in skepticism and control courses, respectively). Critically, the belief categories we derived from the questionnaire were reliably measured: Spearman-
Brown test-retest reliabilities for each belief category, which were based on control students who completed current-belief measures at both time points (and who thus received no intervention or hindsight manipulation; $N=$ 72), ranged from .89 to .97 .

A significant four-way interaction among course (skepticism vs. control), time (pre vs. post), postcourse questionnaire procedure (current beliefs vs. hindsight), and belief category $\left[F(6,1932)=3.83, M S_{\mathrm{e}}=0.32, p=\right.$ $\left..001, \eta_{\mathrm{p}}^{2}=.01\right]$, led us to examine each assessment procedure and category separately. In reporting their current beliefs (see Figure 1A), students in the skepticism course showed significantly greater pre-to-post decreases than did controls in only some of the categories; indeed, the course $\times$ time $\times$ belief category interaction was significant $\left[F(6,1014)=12.15, M S_{\mathrm{e}}=0.33, p<.001, \eta_{\mathrm{p}}^{2}=\right.$ .07]. Except for Judeo-Christian/biblical and creationism beliefs, all belief categories showed greater decreases for skepticism-course students than for controls [for these course $\times$ time interactions, $F \mathrm{~s}(1,169)$ ranged from 12.12 to $72.62, p \mathrm{~s} \leq .001$, and $\eta_{\mathrm{p}}^{2} \mathrm{~s}$ ranged from .07 to .30 ]. Noncreationist Judeo-Christian/biblical beliefs were not

Table 1

Principal Components Loadings (Oblimin Rotation) for Items Selected for Pre- to Postbelief Change Analyses

\begin{tabular}{|c|c|c|c|c|c|c|}
\hline Item (Paraphrase) & Psychic & AltMed & Aliens & Astrology & Omens & Bible/Creation \\
\hline Some people can foresee events & .756 & - & - & - & - & - \\
\hline ESP is real & .690 & - & - & - & - & - \\
\hline Psychically sense family in trouble & .639 & - & - & - & - & - \\
\hline Some dreams predict future events & .626 & - & - & - & - & - \\
\hline Some can communicate with dead & .578 & - & - & - & - & - \\
\hline Herbal remedies preferred over meds & - & .769 & - & - & - & - \\
\hline Alternative meds more effective & - & .758 & - & - & - & - \\
\hline Modern medicine should learn from ancients & - & .670 & - & - & - & - \\
\hline Med based on spirituality over science & - & .369 & - & - & - & - \\
\hline Meditate important for healthy soul, spirit & - & .244 & - & - & - & - \\
\hline Many UFOs actually alien spacecraft & - & - & .858 & - & - & - \\
\hline Some abducted by beings from other planets & - & - & .842 & - & - & - \\
\hline Beings from other planets often visit Earth & - & - & .837 & - & - & - \\
\hline U.S. government hides alien evidence & - & - & .804 & - & - & - \\
\hline Roswell flying saucer crash concealed & - & - & .774 & - & - & - \\
\hline Intelligent life exists on other planets & - & - & .582 & - & - & - \\
\hline Someday I will consult an astrologer & - & - & - & .709 & - & - \\
\hline Astrologers useful consultants on decisions & - & - & - & .676 & - & - \\
\hline Planets/stars affect personality and life events & - & - & - & .670 & - & - \\
\hline Astrology can predict aspects of future & - & - & - & .642 & - & - \\
\hline Nostradamus accurately predicted events & - & - & - & .446 & - & - \\
\hline Breaking a mirror can bring bad luck & - & - & - & - & .823 & - \\
\hline Walking under ladders brings bad luck & - & - & - & - & .799 & - \\
\hline The number 13 is truly unlucky & - & - & - & - & .790 & - \\
\hline Athletes on Sports Illustrated cover jinxed & - & - & - & - & .645 & - \\
\hline Bad things happen on Friday 13 th & - & - & - & - & .628 & - \\
\hline Good luck charms help school performance & - & - & - & - & .602 & - \\
\hline The Biblical Heaven exists & - & - & - & - & - & .896 \\
\hline The Biblical God exists & - & - & - & - & - & .896 \\
\hline The Biblical Hell exists & - & - & - & - & - & .894 \\
\hline Biblical Satan exists & - & - & - & - & - & .875 \\
\hline I am a very religious person & - & - & - & - & - & .873 \\
\hline Humans evolved with no help from God & - & - & - & - & - & -.867 \\
\hline Teach Biblical creation in bio class & - & - & - & - & - & .780 \\
\hline God created plants/animals as seen today & - & - & - & - & - & .679 \\
\hline The Earth is only $6,000-10,000$ years old & - & - & - & - & - & .647 \\
\hline Evolution only a theory; can't be proven & - & - & - & - & - & .623 \\
\hline
\end{tabular}

Note-Psychic, psychics/ESP; AltMed, alternative medicine/healing; Aliens, UFOs/alien abduction; Omens, superstitions/ omens; Bible/Creation, Judeo-Christian/biblical and creationism. 
A

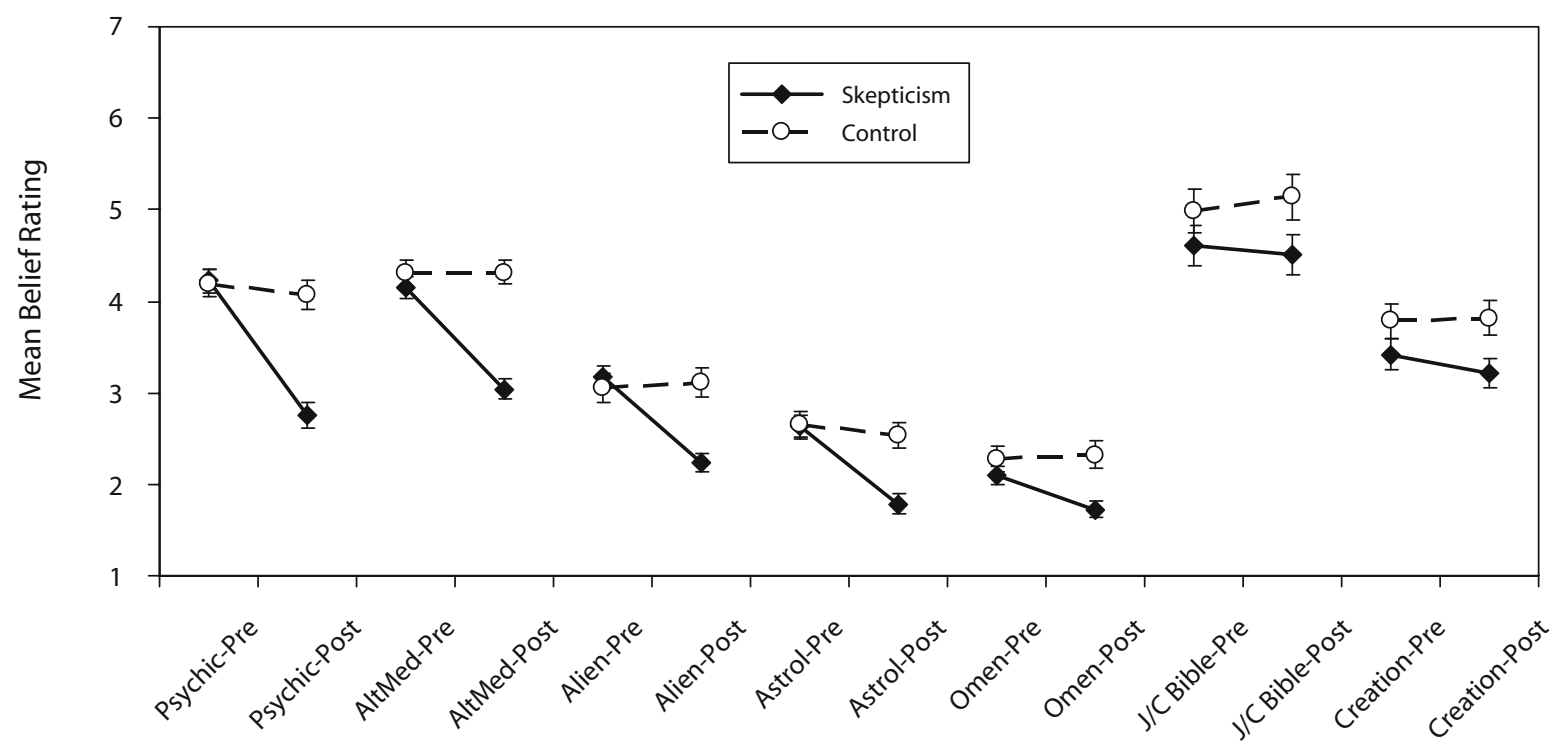

B

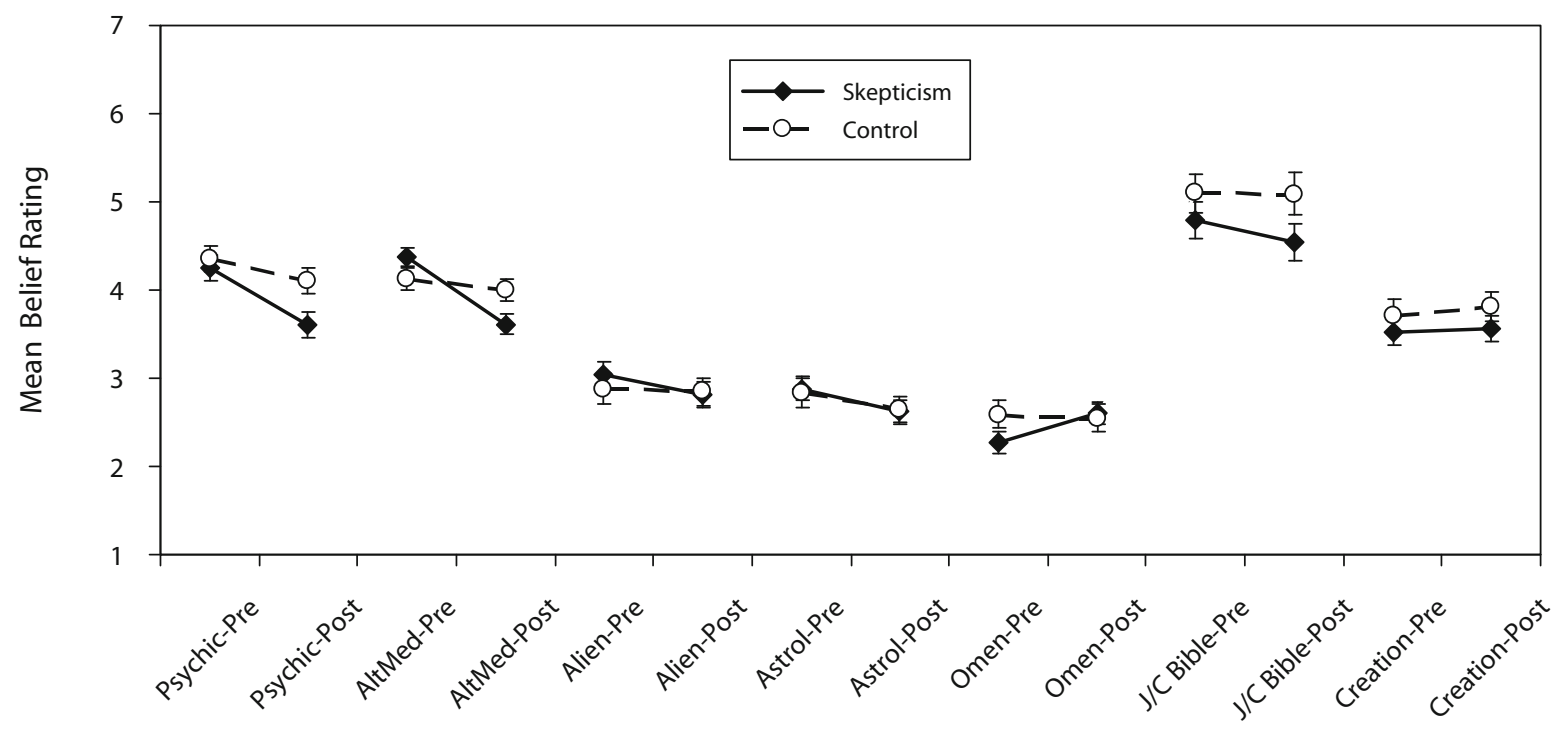

Figure 1. Mean pre- and postcourse belief ratings (on a 7-point scale), for students in skepticism and control courses, across seven topics: psychics/ESP (Psychic); alternative medicine/healing (AltMed); UFOs/alien abduction (Alien); astrology (Astrol); superstitions (Omen); Judeo-Christian/biblical (J/C Bible); and creationism (Creation). (A) Students reporting on their current beliefs at both Time 1 and Time 2. (B) Students reporting current beliefs at Time 1 and attempting to reproduce their Time 1 responses at Time 2. Error bars represent standard errors.

addressed in the course materials, and creationist beliefs were expected to be difficult to change, particularly in the "Bible Belt" of the southeastern U.S.

It was clear, however, that for phenomena related to psychics/ESP, alternative medicine/healing, UFOs/alien abductions, astrology, and superstitions/omens, students in the skepticism course reported themselves to be much more skeptical of the paranormal and of pseudoscience following the course than they were before and reported themselves to be more skeptical than did students in the control courses. Moreover, these significant effects came in the context of skepticism- and control-course students reporting statistically identical beliefs on the precourse measures: The overall main effect of course at Time 1 was nonsignificant $\left[F(1,169)=1.22, M S_{\mathrm{e}}=4.48, p>\right.$ .27], and for each of the five belief categories showing a course $\times$ time interaction above, all main effects of course at Time 1 yielded nonsignificant differences $\left[F_{\mathrm{s}}(1,169)<\right.$ 
$1.16, p s>.28]$. Skepticism- and control-course outcome differences, therefore, were not driven by selection biases.

For students completing the hindsight measure (Figure 1B) - that is, those who attempted to recall their Time 1 responses at Time 2 -the course $\times$ time $\times$ belief category interaction was, again, significant $[F(6,918)=$ 5.84, $\left.M S_{\mathrm{e}}=0.31, p<.001, \eta_{\mathrm{p}}^{2}=.04\right]$. Of most importance, for psychics/ESP and alternative medicine/healing beliefs - the topics covered most intensely by the skepticism course (see below) - skepticism-course students were more likely than controls to remember themselves as more skeptical before the course than they had been [course $X$ time interactions: psychics/ESP, $F(1,153)=6.20, p<.05$, $\eta_{\mathrm{p}}^{2}=.04$; alternative medicine/healing, $F(1,153)=23.83$, $\left.p<.001, \eta_{\mathrm{p}}^{2}=.14\right]$. Whereas skepticism- and controlcourse students reported statistically equivalent psychics/ ESP and alternative medicine/healing beliefs before the courses began [psychics/ESP, $F(1,153)<1$; alternative medicine/healing, $\left.F(1,153)=2.34, M S_{\mathrm{e}}=0.94, p=.13\right]$, skepticism-course students, postcourse, recalled themselves as having been more skeptical than did control students [psychics/ESP, $F(1,153)=4.81, M S_{\mathrm{e}}=1.85, p<$ $.05, \eta_{\mathrm{p}}^{2}=.03$; alternative medicine/healing, $F(1,153)=$ $\left.5.69, M S_{\mathrm{e}}=0.99, p<.05, \eta_{\mathrm{p}}^{2}=.04\right]$. Note that these patterns reflected more than just regression to the mean: Skepticism-course students' Time 2 recollections for both psychics/ESP and alternative medicine/healing were further from the scale midpoint, and further from the Time 1 and Time 2 control-group recollections, than were their Time 1 belief reports.

Above, we claim that psychics/ESP and alternative medicine/healing beliefs changed more than did those of other paranormal topics because of a systematic treatment effect (i.e., a dose-response relation). Whereas approximately eight skepticism-class periods (roughly $10 \mathrm{~h}$ ) were dedicated to psychics/ESP and alternative medicine/ healing topics combined, only four and a half class periods (5.6 h) were devoted to superstitions/omens, UFOs/ alien abduction, and astrology topics combined. To the extent that video materials and live demonstrations increase the vividness, memorability, and long-term impact of messages (see, e.g., Reyes, Thompson, \& Bower, 1980; Ruscio, 2000), moreover, we offer that, across different semesters, psychics/ESP and alternative medicine/healing topics were supplemented by 18-23 videos (ranging from 4 to $60 \mathrm{~min}$ each) and five demonstrations (from 5 to $60 \mathrm{~min}$ each), whereas superstitions/omens, UFOs/ alien abduction, and astrology topics were supplemented by only $2-3$ videos (ranging from 3 to $60 \mathrm{~min}$ each) and only two demonstrations (from 5 to $10 \mathrm{~min}$ each). The two paranormal topic areas that demonstrated significant hindsight-bias effects (and the largest effects on the current-belief questionnaire) thus accounted for almost twice as much class time, and almost five times as many video or demonstration activities, as did the three paranormal topics that showed no hindsight bias; there may be an analogy here to laboratory studies that have found hindsight biases to increase with greater frequency of the "outcome" information (e.g., Wood, 1978).
The evidence strongly suggests that the skepticism course effected real and substantial belief change. Not only did skepticism-course students report themselves to be currently less credulous regarding paranormal claims following the course, but they also recalled themselves as having been more skeptical before the course than they had actually been, at least in two primary topic domains. We might have reason to be skeptical, ourselves, of the current-belief reports, since they may partially reflect demand characteristics. ${ }^{3}$ The hindsight-bias procedure, however, tapped into subjects' beliefs in a way that circumvented demand. Not only has basic laboratory research on hindsight indicated minimal social-desirability or motivational influence (Hawkins \& Hastie, 1990), but it is unlikely here that any particular social demand would have led students to feign or exaggerate their prior skepticism in only two paranormal domains on the hindsight questionnaires while endorsing skepticism in all five (nonbiblical) paranormal domains on the current-belief questionnaire.

In fact, previous research suggests that demand characteristics in our hindsight procedure would have yielded the opposite results (see Ross, 1989). In intervention contexts that lead subjects to expect change (study-skills courses, pain-treatment programs), but in which little objective change actually occurs, people retrospectively adjust their personal recollections "downward" in order to appear more changed (e.g., they recall their initial study skills or initial pain levels as having been worse than they actually were; Conway \& Ross, 1984; Linton \& Melin, 1982). Most relevant to present concerns, such downward adjustments can appear in people's recollections of past attitudes as well: Subordinates whose supervisors completed a managementtraining course showed no objective pre-to-post change in their attitudes about work (commitment to the team, sense of direction), but after their boss's course they remembered themselves as having originally had worse attitudes than they reported at the time (Taylor, Russ-Eft, \& Taylor, 2009). In the context of the present study, then, any such demandinduced biases should have led our skepticism-course students to support their (unfounded) expectation of a change toward skepticism by recalling themselves as having been more credulous than they had actually been, rather than more skeptical than they had been.

\section{CONCLUSION}

Our study exploited the hindsight bias to show that, for several deeply covered topics, educational interventions reduced paranormal beliefs beyond the effects of demand characteristics. Of broader significance, the findings indicate that any intervention program that creates and measures psychological change may circumvent demand effects by harnessing hindsight: People who truly change may misremember themselves as having been just as they are now. Indeed, regarding the pseudoscientific claims of psychics and alternative healers, our skepticismcourse students believed that they had "pooh-poohed it all along." 


\section{AUTHOR NOTE}

We thank Jackie White and Janet Boseovski for providing controlgroup data from their courses. Rob Guttentag, Scott Lillienfeld, and Michael Shermer provided helpful materials and discussion regarding development of the skepticism course. Correspondence concerning this article should be addressed to M. J. Kane, Department of Psychology, 321 McIver St., University of North Carolina, Greensboro, NC 27412 (e-mail: mjkane@uncg.edu).

\section{REFERENCES}

Aarnio, K., \& Lindeman, M. (2005). Paranormal beliefs, education, and thinking styles. Personality \& Individual Differences, 39, 1227 1236. doi:10.1016/j.paid.2005.04.009

BANZIGER, G. (1983). Normalizing the paranormal: Short-term and longterm change in belief in the paranormal among older learners during a short course. Teaching of Psychology, 10, 212-214. doi:10.1207/ s15328023top1004_6

Bem, D. J., \& McConnell, H. K. (1970). Testing the self-perception explanation of dissonance phenomena: On the salience of premanipulation attitudes. Journal of Personality \& Social Psychology, 14, 23-31.

Broch, H. (2000). Save our science: The struggle for reason at the university. Skeptical Inquirer, 24(3), 34-39.

Calvin, S. (2009). Crazy ideas 101: How to teach skeptical thinking in the classroom. Skeptic, 15(1), 14-17.

Collins, L. M., Graham, J. W., Hansen, W. B., \& Johnson, C. A. (1985). Agreement between retrospective accounts of substance use and earlier reported substance use. Applied Psychological Measurement, 9, 301-309. doi:10.1177/014662168500900308

Conway, M., \& Ross, M. (1984). Getting what you want by revising what you had. Journal of Personality \& Social Psychology, 47, 738 748. doi:10.1037/0022-3514.47.4.738

Cronbach, L. J., \& Furby, L. (1970). How we should measure "change"-Or should we? Psychological Bulletin, 74, 68-80. doi:10.1037/h0029382

Dougherty, M. J. (2004). Educating believers: Research demonstrates that courses in skepticism can effectively decrease belief in the paranormal. Skeptic, 10(4), 31-35.

Eмme, E. E. (1940). Modification and origin of certain beliefs in superstition among 96 college students. Journal of Psychology, 10, 279-291.

Festinger, L. (1957). A theory of cognitive dissonance. Evanston, IL: Row, Peterson.

Field, N. P., Thompson, L. W., \& Gallagher-Thompson, D. (2006). Impact of current grief on memory for past grief in spousal bereavement. Memory, 14, 297-306. doi:10.1080/09658210500243747

FischHOFF, B. (1975). Hindsight is not equal to foresight: The effect of outcome knowledge on judgment under uncertainty. Journal of Experimental Psychology: Human Perception \& Performance, 1, 288299. doi:10.1037/0096-1523.1.3.288

FischHoff, B. (1977). Perceived informativeness of facts. Journal of Experimental Psychology: Human Perception \& Performance, 3, 349358.

Gilliland, A. R. (1930). A study of the superstitions of college students. Journal of Abnormal \& Social Psychology, 24, 472-479. doi:10.1037/ h0071815

Goode, E. (2002). Education, scientific knowledge, and belief in the paranormal. Skeptical Inquirer, 26(1), 24-27.

Gray, T. (1985). Changing unsubstantiated belief: Testing the ignorance hypothesis. Canadian Journal of Behavioural Science, 17, 263-270. doi:10.1037/h0080144

Greenwald, A. G., Spangenberg, E. R., Pratkanis, A. R., \& EskeNAZI, J. (1991). Double-blind tests of subliminal self-help audiotapes. Psychological Science, 2, 119-122. doi:10.1111/j.1467-9280.1991 .tb00112.x

Hasher, L., Attig, M. S., \& Alba, J. W. (1981). I knew it all along: Or, did I? Journal of Verbal Learning \& Verbal Behavior, 20, 86-96. doi:10.1016/S0022-5371(81)90323-6

Hawkins, S. A., \& Hastie, R. (1990). Hindsight: Biased judgments of past events after the outcomes are known. Psychological Bulletin, 107, 311-327. doi:10.1037/0033-2909.107.3.311

Hertzog, C., \& Nesselroade, J. R. (2003). Assessing psychological change in adulthood: An overview of methodological issues. Psychology \& Aging, 18, 639-657. doi:10.1037/0882-7974.18.4.639

Hoogstraten, J. (1979). Pretesting as determinant of attitude change in evaluation research. Applied Psychological Measurement, 3, 25-30. doi:10.1177/014662167900300103

Jones, W. H., \& ZuSNE, L. (1981). Teaching anomalistic psychology. Teaching of Psychology, 8, 78-82. doi:10.1207/s15328023top0802_3

KIRSCH, I. (1985). Response expectancy as a determinant of experience and behavior. American Psychologist, 40, 1189-1202. doi:10.1037/ 0003-066X.40.11.1189

Laney, C., Kaasa, S. O., Morris, E. K., Berkowitz, S. R., Bernstein, D. M., \& LofTus, E. F. (2008). The red herring technique: A methodological response to the problem of demand characteristics. Psychological Research, 72, 362-375. doi:10.1007/s00426-007-0122-6

Lewinsohn, P. M., \& Rosenbaum, M. (1987). Recall of parental behavior by acute depressives, remitted depressives, and nondepressives. Journal of Personality \& Social Psychology, 52, 611-619. doi:10.1037/0022-3514.52.3.611

Linton, S. J., \& Melin, L. (1982). The accuracy of remembering chronic pain. Pain, 13, 281-285. doi:10.1016/0304-3959(82)90017-3

LofTus, E. F. (1979). Eyewitness testimony. Cambridge, MA: Harvard University Press.

LORD,F.M.(1956). The measurement of growth. Educational \& Psychological Measurement, 16, 421-437. doi:10.1177/001316445601600401

LORD, F. M. (1967). A paradox in the interpretation of group comparisons. Psychological Bulletin, 68, 304-305. doi:10.1037/h0025105

MarkUs, G. B. (1986). Stability and change in political attitudes: Observed, recalled, and "explained." Political Behavior, 8, 21-44. doi:10.1007/BF00987591

Markus, H., \& Kunda, Z. (1986). Stability and malleability of the selfconcept. Journal of Personality \& Social Psychology, 51, 858-866. doi: $10.1037 / 0022-3514.51 .4 .858$

McBurney, D. H. (1976). ESP in the psychology curriculum. Teaching of Psychology, 3, 66-69. doi:10.1207/s15328023top0302_5

Moore, D. W. (2005, June 16). Three in four Americans believe in paranormal. Gallup News Service. Retrieved from www.gallup.com/ poll/16915/three-four-americans-believe-paranormal.aspx

Morier, D., \& KeEPORTS, D. (1994). Normal science and the paranormal: The effect of a scientific method course on students' beliefs. $R e$ search in Higher Education, 35, 443-453.

Nesselroade, J. R., Stigler, S. M., \& Baltes, P. B. (1980). Regression toward the mean and the study of change. Psychological Bulletin, 88, 622-637. doi:10.1037/0033-2909.88.3.622

Newport, F., \& Strausberg, M. (2001, June 8). Americans' belief in psychic and paranormal phenomena is up over last decade. Gallup News Service. Retrieved from www.gallup.com/poll/4483/ americans-belief-psychic-paranormal-phenomena-over-last-decade .aspx

OrNe, M. T. (1962). On the social psychology of the psychological experiment: With particular reference to demand characteristics and their implications. American Psychologist, 17, 776-783. doi:10.1037/ h0043424

Reyes, R. M., Thompson, W. C., \& Bower, G. H. (1980). Judgmental biases resulting from differing availabilities of arguments. Jour nal of Personality \& Social Psychology, 39, 2-12. doi:10.1037/0022 $-3514.39 .1 .2$

RICE, T. W. (2003). Believe it or not: Religious and paranormal beliefs in the United States. Journal for the Scientific Study of Religion, 42 95-106. doi:10.1111/1468-5906.00163

Ross, M. (1989). Relation of implicit theories to the construction of personal histories. Psychological Review, 96, 341-357. doi:10.1037/0033 $-295 X .96 .2 .341$

RUBIN, D. B. (1974). Estimating causal effects of treatments in randomized and nonrandomized studies. Journal of Educational Psychology, 66, 688-701. doi: 10.1037/h0037350

Ruscio, J. (2000). Risky business: Vividness, availability, and the media paradox. Skeptical Inquirer, 24(2), 22-26.

SwORDS, M. D. (1990). Using the study of anomalies to enhance critical thinking in the classroom. Journal of Scientific Exploration, $\mathbf{4}$ 123-136.

TAYlor, P. J., Russ-Eft, D. F., \& TAYlor, H. (2009). Gilding the outcome by tarnishing the past: Inflationary biases in retrospective 
pretests. American Journal of Evaluation, 30, 31-43. doi:10.1177/ 1098214008328517

TовасҮК, J. J. (1983). Reduction in paranormal belief among participants in a college course. Skeptical Inquirer, 8(1), 57-61.

Wesp, R., \& Montgomery, K. (1998). Developing critical thinking through the study of paranormal phenomena. Teaching of Psychology, 25, 275-278.

Wilson, T. D., \& BrekKe, N. (1994). Mental contamination and mental correction: Unwanted influences on judgments and evaluations. Psychological Bulletin, 116, 117-142. doi:10.1037/0033 $-2909.116 .1 .117$

Wood, G. (1978). The knew-it-all-along effect. Journal of Experimental Psychology: Human Perception \& Performance, 4, 345-353. doi:10.1037/0096-1523.4.2.345

\section{NOTES}

1. Only some of the samples from Dougherty (2004) and Gray (1985) were compared with controls; Wesp and Montgomery (1998) compared skepticism-course students with controls in thinking skills, but they did not evaluate students' beliefs.
2. Because the alternative medicine/healing composite measure included two items with fairly low factor loadings (see Table 1), we reran the relevant ANOVAs using a second composite that included only the three high-loading items. This three-item composite yielded slightly lower mean endorsement ratings than those we report for the full, fiveitem composite, but the statistical patterns (all main effects and interactions) were unchanged.

3. Of course, with the current-belief procedure there is simply no way to determine exactly how much influence demand characteristics might be having on subjects' responses (this is what motivated our use of the hindsight procedure, after all). At the same time, we do not believe that students' reports of their current beliefs were driven entirely by demand characteristics, because they reported belief change selectively. Note that skepticism students did not report being less believing of creationism claims at the end of the course, despite the devotion of significant lecture and reading material to discussing creationism as a pseudoscientific system. If demand had been overwhelmingly responsible for students' belief reports, they would have indicated significant belief change in creationism.

(Manuscript received July 24, 2009;

revision accepted for publication October 22, 2009.) 